Review Article

\title{
Direct access to physical therapy for the patient with musculoskeletal disorders, a literature review
}

LeOnardo Piano, PT, OMPT ${ }^{1)^{*}}$, FilipPo Maselli, PT, OMPT, MSc ${ }^{2-4)}$, Antonello Viceconti, PT, OMPT, MSc ${ }^{3,4)}$, Silvia Gianola, PT, OMPT, $\mathrm{MSc}^{5,6)}$, Aldo Ciuro, PT, OMPT, MSc ${ }^{4,7)}$

1) Unit of Rehabilitation and Functional Recovery, Casa di Cura La Residenza: Via Roma 1, 12050 Rodello, Italy

2) Sovrintendenza Sanitaria Regionale Puglia INAIL, Italy

3) DINOGMI Department, University of Genoa, Campus of Savona, Italy

4) PG Cert in Rehabilitation of Musculoskeletal Disorders, DINOGMI Department, University of Genoa, Campus of Savona, Italy

5) Center of Biostatistics for Clinical Epidemiology, School of Medicine and Surgery, University of Milano-Bicocca, Italy

6) Clinical Epidemiology Unit, I.R.C.C.S. Orthopedic Institute Galeazzi, Italy

7) Madonna delle Grazie Hospital, Italy

\begin{abstract}
Purpose] To present legislation comparing direct and referred access — or other measures — to physical therapy. The focus is on the management of the most burdensome musculoskeletal disorders in terms of regulations, costs, effectiveness, safety and cost-effectiveness. [Methods] Main biomedical databases and gray literature were searched ranging from a global scenario to the analysis of targeted geographical areas and specifically Italy and the Region Piedmont. [Results] legislation on Direct Access highlights inconsistencies among the countries belonging to World Confederation for Physical Therapy. Direct Access could be an effective, safe and efficient organization model for the management of patients with musculoskeletal diseases and seems to be more effective safer and cost effective. [Conclusion] Direct Access is a virtuous model which can help improve the global quality of physical therapy services. Further studies are required to confirm this approach and determine whether the findings of the present overview can be replicated in different countries and healthcare systems.

Key words: Physical therapy specialty, Musculoskeletal diseases, Referral and consultation
\end{abstract}

(This article was submitted Nov. 11, 2016, and was accepted Feb. 7, 2017)

\section{INTRODUCTION}

Musculoskeletal disorders (MSD) are one of the most common health problems leading to substantial disability and financial burden and over the past few years they have increased substantially ${ }^{1,2)}$. The most frequently encountered MSDs are low back pain (LBP), neck pain (NP) and osteoarthritis (OA). The estimated prevalence of these MSDs ranges from 9.4\% (95\% CI 9.0 to 9.8 ) for $\mathrm{LBP}^{3}$ ) , to $4.9 \%$ (95\% CI 4.6 to 5.3) as for NP ${ }^{4}$ and 3.8 (95\% CI $3.6 \%$ to $4.1 \%$ ) for knee OA (the most prevalent and burdensome OA throughout the world $)^{5}$. Furthermore, MSD is a major clinical and social burden since LBP is the first leading cause of Years Lived with Disability (YLDs), whereas NP and OA rank among the top ten causes of global YLDs according to Global Burden of Disease 2013 ${ }^{1)}$.

In addition to their prevalence and social impact of MSD are likely to increase since the growing levels of overweight and

*Corresponding author. Leonardo Piano (E-mail: 1.piano@hotmail.it)

(C2017 The Society of Physical Therapy Science. Published by IPEC Inc.

(c) (i) $(-)$ This is an open-access article distributed under the terms of the Creative Commons Attribution Non-Commercial No DerivacC. 
sedentary lifestyles which seem to be strongly associated with $\mathrm{MSD}^{1-5)}$.

MSD can be managed through Direct Access (DA), that is the ability of the patient to self-refer directly to the physical therapist, avoiding intermediate steps through other health professionals that may lengthen the path to recovery ${ }^{6}$. DA and physical therapists' Independence are increasingly in the forefront of the present debate on the modern health service. For instance, the American Physical Therapy Association (APTA) Vision 2020 program considers the autonomous practice and DA as two relevant topics ${ }^{7}$.

Despite a growing literature supporting DA, many countries do not allow this organizational model in their public health services which may be due to a number of reasons, such as politics but also clinical issues that would warrant not to adopt DA all over the world. Unsafe practice, with a potentially risk for patients, and higher costs associated to DA are two of the most frequently raised topics. However, this issues seem not to be supported by strong evidence suggesting physical therapists should not directly manage patients with MSD.

To endorse a paradigmatic change in the global organization model and promote DA as a new approach all the issues related to clinical, economics and legislation topics have to be addressed.

The present research article aims to provide a detailed examination of DA to physical therapy by patients suffering from MSD presenting:

(i) the legislation on DA starting from an international framework and then homing in on Italy. Finally, we present a regional example (i.e. Piedmont); and

(ii) evidence on the effectiveness, safety and cost-effectiveness of DA compared with Referred Access (RA) and other approaches.

\section{METHODS}

The main biomedical databases (i.e. Medline, PEDro, Cochrane Library, EMBASE, CINHAL, ISI, Scopus), Google Scholar and gray literature (theses, preprints, working papers, technical reports) were searched to identify relevant studies. Data on economic costs were retrieved on institutional database (i.e. Ministry of Health official website, ISTAT website). Reference lists of potentially eligible studies were also considered.

In order to find out the most suitable and specific papers regarding the topic, a PICO search strategy was built according to these following key words: "Musculoskeletal Diseases", "Back Pain", "Osteoarthritis", "Physical Therapy", "Direct Access", "Self-Referral", "Effectiveness, Outcome". A full search strategy is reported in Appendix 1. The last search was run in October 2016 and last update was performed in January 2017. Two researchers (LP, FM) independently screened all studies for eligibility by titles and abstracts. Full texts were then evaluated for inclusion.

Data on DA worldwide, in Europe and Italy and the organization and economic framework are reported. Outcomes of effectiveness, safety and cost-effectiveness of DA for MSD were investigated. Specifically, the DA group, that received a primary contact physical therapy assessment or treatment, and RA as control group which received a general practitioner referral to physical therapy or other interventions (i.e. drugs) were compared.

\section{RESULTS}

DA was first established in 1957 in the U.S.: Nebraska was the first state to introduce DA ${ }^{8)}$. In the 1970's the Australian Physiotherapy Association (APA) removed the principle stating that "for a Physical Therapist -member of the APA -it is ethical to visit a patient only after a doctor's (or a registered dentist's) referral". Since no law precluded DA in Australia, the move of APA has substantially "changed the thinking more than a law", says Jonathan Kruger in his paper"). He says that the 1976 statement was the most important move in the history of physical therapy ${ }^{9}$ ). In the past thirty years, more and more countries have introduced a specific legislation for DA in physical therapy. Prue Galley, an Australian physical therapist, was the first to push for the recognition of the profession. She said that "as physical therapists we have the knowledge, the courage, the will and the mind to complete this step towards independence, even if we will be asked for a more responsibility, dedication and self-discipline for all of us" ${ }^{\prime 10)}$.

The WCPT has confirmed that DA and self-referral to physical therapy is clinically and cost effective ${ }^{11)}$. However, DA is not the same all over the world as illustrated by the WCPT survey published in January 2013 that showed Africa was the most unrestricted continent as for $\mathrm{DA}^{11)}$; a patient can choose his/her physical therapist both in the public and in the private health services whereas in the other countries the rate of DA drops to $50 \%$ and was mainly reserved to the private health services ${ }^{11)}$. In most of the states in the U.S., for example, DA is a structured service mainly focused on MSD ${ }^{11-14)}$.

In particular, Shoemaker ${ }^{15}$ ) analyzed the U.S. framework focusing on the main contributor and competitor factors. The author underlined the safety of this model and its non-inferiority compared with the medical-referral approach and highlights the higher quality of the service and the higher therapeutic outcomes ${ }^{15}$.

In a descriptive study, Bury \& Stokes ${ }^{16)}$ examined the DA legislation among WCPT member organizations (MOs). They reported a response rate of $68 \%(72 / 106)$, DA was reported by $58 \%$ of the respondents, with a higher prevalence in private settings.

Like the rest of the world, Europe too is not all the same: Bury \& Stokes ${ }^{17}$ ) examined the European DA using the same 
methodology as the one employed in the worldwide study ${ }^{16)}$.

Twenty-three of the twenty-seven WCPT MOs participated in the survey. DA is allowed by the legislation or by the professional profile in twelve countries (52\% of participants). Just like in the rest of the world, DA in Europe is more common in the private $(83 \%)$ than in the public health services $(22 \%)^{17)}$.

In 2006 DA was introduced in the Netherlands ${ }^{18,19)}$ at the same time, some publications focused their attention on the progressive features of DA which proved a worthy model of organization that is discussed in the present article.

In Italy access to public rehabilitative services which include physical therapy requires the referral by a Physical and Rehabilitation Medicine consultant who evaluates and assesses the needs for physical therapy through the Individual Rehabilitation Project (PRI in Italian).

Nowadays DA is only possible in private health services: patients can refer to private physical therapists who manage the rehabilitation path of the patient, according to the job description (Ministerial Directive 741/1994) that states "physical therapists can work autonomously and/or with other health professionals, (e.g. surgeons, nurses, ...) in order to address patients' health demands" ${ }^{20)}$.

Notwithstanding the Italian framework is not homogeneous neither in private health services: DA is also forbidden in some of the twenty Italian regions due to the local regulations that may differ from the national ones.

For instance, Piedmont's Regional Law 10-5605 ${ }^{21}$ states patients should be examined by a rehabilitation consultant if affected by a given number of clinical complaints ${ }^{21}$.

This approach is not clear and is inconsistent with a physical therapist's job description that reads: "they act following a medical diagnosis; he/she designs - also in a multidisciplinary team — the rehabilitation program aimed at identifying and addressing patient health needs; they autonomously manage the patient to rehabilitate the motor, psycho-motor and cognitive impairments using instrumented, manual and occupational therapies (...)"21).

As for rehabilitation costs, in its 2012-13 Report the "Ministero della Salute" (i.e. Ministry of Health) gave the following figures: the total economic burdens were $€ 1,882,829,000$ in 2012 ( $€ 91,600,000$ in the Public and $€ 1,791,229,000$ in the Private Health Service) and $€ 1,878,387,000$ in 2013 ( $€ 86,530,000$ in the Public and $€ 1,791,857,000$ in the Private Health Service) ${ }^{22,23)}$.

As for Piedmont, according to the Ministry of Health, in 2012 only $48 \%$ of the requests for a physical and rehabilitation medicine visits were met in the first 10 days, whereas $25.1 \%$ took a 1 month from when the patients requested the appointment $^{23)}$. In 2013 the overall picture was comparable, even if there was a small improvement: about $50 \%$ of visits within 10 days, and $25.7 \%$ after 1 month $^{23}$. No information about clinical conditions nor about the beginning of the rehabilitation treatment emerge from these data.

As for the previously mentioned data on Piedmont, the cost of rehabilitation in 2012 was $€ 163,723,000$ (€ 30,099,000 in the Public and $€ 133,624,000$ in the Private Health Service) whereas in 2013 it came to $€ 172,196,000$ (€ 37,627,000 in the Public and $€ 134,569,000$ in the Private Health Service), with an increase of about 5\% compared to the previous year ${ }^{23)}$.

To consider DA as a valid therapeutic option in the management of MSD, its therapeutic approach must be assessed and the following questions answered: 1) is it effective and safe for the patient, and 2) is it cost-effective for the health care systems and the community.

DA was found to be effective displaying better outcomes at discharge when compared to referral to physical therapy by a physician ${ }^{24)}$. Leemrijse et al. ${ }^{18)}$ reported that the percentage of patients who fully reached their goals at the end of the treatment was $9 \%$ more in the DA group $(72.6 \%$ vs. $63.3 \%)$. Holdsworth ${ }^{25)}$ and Webster ${ }^{26)}$ noticed that the percentage of patients who completed their therapeutic route was equal to $79 \%$ in the DA group, compared to the $60 \%$ in the referred group. In addition, Hackett et al. ${ }^{27)}$ reported that the average number of lost working days was 17 days less in the DA group if compared to the referred group.

Prompt intervention after injury is the key to patient satisfaction when DA is compared to RA: Nordeman et al. ${ }^{28)}$ in his randomized controlled trial assessed the effects of physical therapy via DA in a sub-acute LBP population comparing an early management (early access group-EA) to a late management (late access-LA) after their inclusion. EA showed improvement in the patient's mean pain perception (assessed with 10-points Borg's Scale) from baseline after 6 months (EA $=-3.0[95 \% \mathrm{CI}$ 2.4 to 3.6]; $\mathrm{LA}=-2.0$ [95\% CI 1.2 to 2.8$] \mathrm{p}=0.025$ ). No significant differences were observed in secondary outcomes (disability, risk for long-term disability and sick leave) at the discharge and at 6-month follow up.

Zigenfus et al. ${ }^{29)}$ conducted on acute LBP worker population showed better results (compared to the number of total access needed) in the experimental group (3.1 [95\% CI 3.0 to 3.2]) in which the first visit took place on the same day or the day after, compared to later access $(3.4$ [95\% CI 3.3 to 3.5] and 3.9 [95\% CI 3.8 to 4.1]). In the second group the first visit was granted between 2 and 8 days after and between 8 and 197 days in the third group $(\mathrm{p}<0.01)$. Results were better for the early access also for the case duration $(9.8$ [95\%CI 9.4 to 10.3] days in the first group, 12.3 [95\%CI 11.8 to 12.8] in the second group and 16.5 [95\% CI 15.2 to 17.8 ] in the third group, $\mathrm{p}<0.01)$, the duration of restricted work $(8.1$ [95\%CI 7.7 to 8.5$]$ days in the first group, 9.9 [95\% CI 9.5 to 10.3$]$ in the second group and 13.4 [95\% $\mathrm{CI} 12.3$ to 14.5$]$ in the third group, $\mathrm{p}<0.01)$ and the days off work $(4.5$ [95\% CI 4.3 to 4.7 ] days in the first group, 5.2 [95\% 5 I 5.0 to 5.4 ] in the second group and 7.0 [95\%CI 6.6 to 7.6$]$ in the third group, $\mathrm{p}<0.05)$.

Although the two above mentioned studies compared two interventions, both in DA regimen (delayed versus early) and the study by Zigenfus et al. ${ }^{29)}$ represents the characteristics of a DA intervention (i.e. prompt intervention in the same day) in 
a more effective manner, while the subjects in the study by Nordeman et al. ${ }^{28)}$ could be evaluated and treated even after two days from the presentation.

Daker-White et al. ${ }^{30}$ studied the difference between the evaluation and treatment modalities made directly by adequately trained physical therapists (orthopedic physical therapy specialists) and those of a group of sub-consultant surgical staff in the initial assessment and management of new general practitioner referrals to orthopedic outpatients. Patients' perceived satisfaction (measured with a 37-item instrument, based on the Boston Patient Expectations and Satisfaction Questionnaire and the Leeds Patient Satisfaction Scale, where a lower score (means greater satisfaction) was significantly better $(p=0.001)$ for the group evaluated by the physical therapists versus the control group (mean differences $=3.0$ [95\% CI 1.3 to 4.9 ] . No significant differences were found for clinical outcomes and in the cost effectiveness analysis, although there were significant differences in hospital costs when calculated at initial consultation: these costs were greater in the group managed by junior doctors compared to the one managed by physical therapists and are related to a higher number of investigation (especially $\mathrm{x}$-rays) and the larger number referred for orthopedic surgery. In addition, doctors were more likely to prescribe injections. The questionnaire also reported how physical therapists were much more likely than doctors to give advice and reassurance to the patient and this could explain the difference in patients' satisfaction: the latter may correlate to the fact that physical therapists probably spend more time with their patients. No data about the duration of the visits were available which is why we could not draw any conclusions.

The clinical trial by Taylor et al. ${ }^{31)}$ showed how the presence of a physical therapists for the management of simple peripheral musculoskeletal injuries in the emergency department reduces the length of stay by 59.5 [95\%CI 38.4 to 80.6 ] (the difference between arrival and departure time), waiting time to 25 minutes [95\% CI 12.1 to 38.0] (the difference between the arrival time and the time of initial assessment), the treatment time of 34.9 minutes [95\%CI 16.2 to 53.6] (the difference between medical or physical therapy assessment and departure time). Moreover, more than $82 \%$ of patients managed by primary contact physical therapists were satisfied with their management whereas " $96 \%$ of emergency department staff confirmed that primary contact physical therapists had appropriate skills and knowledge to provide appropriate emergency care". No significant differences were observed in the number of re-presentations to the emergency department within 4 weeks (10\% in both groups) and in referrals for radiology (69\% in the first group and $77 \%$ in the second group).

Although the context in which the data were collected in this study concern a particular situation (i.e. physical therapists in emergency departments), this organizational model could be compared or assimilated to those we commonly refer to as DA, or rather provide the patient's first contact with the physical therapists avoiding the first contact by a doctor.

Daker-White $\mathrm{G}$ et al. ${ }^{30}$ ) examined the effects of introducing a physical therapist to assist an Orthopedic Surgeon in the hospital unit to reduce the waiting list: the physical therapists acted as a filter, selecting which patient required a more scrutinized procedure referring them to a consultant for an assessment or to another healthcare professional to continue the treatment.

Table 1 lists the most relevant studies on effectiveness of DA for patients with MSD.

Safety of the patient managed through DA was also found to be as secure as medical referred model of care.

Moore et al. ${ }^{32}$, published a retrospective observational study on a military sample from the US army. Fifty thousand seven hundred and ninety-nine patients were assessed during a period of 40 months by physical therapists without any adverse events being recorded. The authors underlined the risk of adverse events in a DA regimen was equivalent to the referral-based setting. This result could be a solid starting point to promote $\mathrm{DA}^{32)}$. Childs et al. ${ }^{33)}$ analyzed the evaluation capacity and the competences required to physical therapist managing MSD compared to medical doctors' expertise and skills: interestingly, results showed that expert physical therapists specialized in musculoskeletal disorders possessed better skills and knowledge for MSD assessment compared to most medical specialists except for orthopedic surgeons. Furthermore, physical therapist students tended to have higher levels of knowledge to assess MSD than all trainee doctors. A recent review by Foster et al. ${ }^{34)}$ on UK and Danish patients' musculoskeletal managing model underlined a lower competence of medical doctors to evaluate and manage.

Recent literature has focused on the potential adverse events caused by musculoskeletal physical therapists (or other professions that implies a manual therapy approach). In a review that includes 8 cohort studies and 36 RCTs, Carnes et al. ${ }^{35)}$, examined the adverse events categorized in severe, moderate or mild based on the Delphi consensus published on the same year. Review results indicate a $50 \%$ probability of developing a mild-to-moderate adverse event following a manual therapy session. Such events subside in the 72 hours that follow. On the other hand, the severe adverse events are infrequent, less frequent compared to those caused by medication treatment. Recently, other studies have focused on the cervical spine region; data on the adverse events reflects qualitatively and quantitatively the results of other bigger studies ${ }^{36,37)}$ such as the one of Carnes et al. ${ }^{35)}$ mentioned before. However, as the quality of the methods used was not always up to standard and given the heterogeneity of the assessment approach, definitive conclusion cannot be taken.

A recent retrospective study by Mintken et al. ${ }^{38)}$ investigated whether DA in a university setting put patients at risk for adverse events related to their management: 12976 patients with MSD were managed by 10 physical therapists with an average of 8.8 (SD 5.9; range 0 to $19 \mathrm{yrs)} \mathrm{years} \mathrm{of} \mathrm{experience.} \mathrm{No} \mathrm{adverse} \mathrm{event,} \mathrm{as} \mathrm{defined} \mathrm{by} \mathrm{Moore} \mathrm{et} \mathrm{al.}{ }^{32}$ ), was reported. Malpractice in PT is extremely rare and only a total of 664 reported malpractice payments were attributed to physical therapists in the National Practitioner Data Bank during a 14 year period from 1991 to 2004.

Furthermore, DA costs seem to be lower for the various stakeholders involved in the management of musculoskeletal disorders (i.e. patients, health insurance, health care systems). In their systematic review Ojha et al. ${ }^{24)}$ included four quasi- 
Table 1. Effectiveness of DA compared to RA or other interventions

\begin{tabular}{|c|c|c|c|c|c|c|}
\hline Reference & Design & Patient(s) & Intervention & Comparison & Main outcomes & Main results \\
\hline \multicolumn{7}{|c|}{ Effectiveness of DA } \\
\hline $\begin{array}{l}\text { Ojha et al. } \\
2014\end{array}$ & SR & MSD & DA & RA & $\begin{array}{l}\text { Health care costs } \\
\text { Number of visits } \\
\text { Patient outcomes } \\
\text { Patients' satisfaction }\end{array}$ & $\begin{array}{l}\text { Lower costs in DA group } \\
\text { Better outcomes and higher } \\
\text { satisfaction in DA group }\end{array}$ \\
\hline $\begin{array}{l}\text { Nordeman } \\
\text { et al. } 2006\end{array}$ & $\mathrm{RCT}$ & Subacute LBP & EA to PT & Waiting list & $\begin{array}{l}\text { Pain intensity (Borg) } \\
\text { Disability (Roland } \\
\text { Morris) }\end{array}$ & $\begin{array}{l}\text { Lower pain intensity at } 6 \text { months } \\
\text { for EA compared to control } \\
\text { group }(p<0.05)\end{array}$ \\
\hline $\begin{array}{l}\text { Zigenfus } \\
\text { et al. } 2000\end{array}$ & $\mathrm{RCT}$ & $\begin{array}{l}\text { Workers with } \\
\text { Acute LBP }\end{array}$ & EA to PT & $\begin{array}{l}\text { Delayed } \\
\text { access to } \\
\text { physical } \\
\text { therapy }\end{array}$ & $\begin{array}{l}\text { Number of visits } \\
\text { Restricted workdays } \\
\text { Duration }\end{array}$ & $\begin{array}{l}\text { Fewer physician visits in EA } \\
\text { Fewer restricted workdays and } \\
\text { days away from work in EA } \\
\text { Shorter duration in EA }\end{array}$ \\
\hline $\begin{array}{l}\text { Daker- } \\
\text { White et al. } \\
1999\end{array}$ & $\mathrm{RCT}$ & $\begin{array}{l}\text { MSD in an } \\
\text { orthopedic } \\
\text { ward }\end{array}$ & DA & $\begin{array}{l}\text { Orthopedic } \\
\text { surgeon } \\
\text { consult }\end{array}$ & $\begin{array}{l}\text { Pain, } \\
\text { Disability } \\
\text { Participation }\end{array}$ & $\begin{array}{l}\text { No differences between groups } \\
\text { Higher satisfaction in DA } \\
\text { Lower direct hospital costs in } \\
\text { DA group ( } \mathrm{p}<0.00001 \text { ) } \\
\text { Lower x-rays and referral to } \\
\text { orthopedics in DA }\end{array}$ \\
\hline $\begin{array}{l}\text { Taylor et al. } \\
2011\end{array}$ & $\begin{array}{l}\text { Prospective } \\
\text { non-randomized } \\
\text { controlled trial. }\end{array}$ & $\begin{array}{l}\text { MSD in } \\
\text { Emergency } \\
\text { Department }\end{array}$ & $\begin{array}{l}\text { DA } \\
\text { (primary } \\
\text { contact) }\end{array}$ & $\begin{array}{l}\text { RA } \\
\text { (secondary } \\
\text { contact) }\end{array}$ & $\begin{array}{l}\text { LOS } \\
\text { Waiting time } \\
\text { Treatment time } \\
\text { Request for x-rays, } \\
\text { Patients' satisfaction }\end{array}$ & $\begin{array}{l}\text { Reduction in LOS in DA group } \\
\text { Reduction in waiting times in } \\
\text { DA group } \\
\text { Higher satisfaction in DA group }\end{array}$ \\
\hline
\end{tabular}

Table 1 synthesized the main literature about clinical effectiveness of DA for patients with MSD. DA: direct access to physical therapy; EA: early access; LBP: low back pain; LOS: length of stay; RA: referred access by a physician; RCT: randomized controlled trial; SMT: spinal manipulative therapy; SR: systematic review

experimental studies (i.e. non-randomized clinical trials) $)^{12,27,40,41)}$ that examined various economic aspects related to DA. Three of these studies ${ }^{27,40,41)}$ showed that DA made it possible to significantly reduce the costs for musculoskeletal disorders management, number of appointments and prescriptions for imaging tests. Holdsworth et al. ${ }^{40)}$ found a reduction in patients' expenses when self-referring to physical therapy, with relevant annual savings of about two million pounds if calculated for the entire Scottish health care system where the study was conducted. In her recent essay about DA and the UK health system, Karen Middleton ${ }^{39)}$ focused on the money-saving: about 30\% of GP consultations may be for MSD, so that DA could help to save money and number of GP visits.

Table 2 lists studies included in our review highlighting current knowledge of adverse or undesired effects of physical therapy in managing MSD.

From an economic point of view, the studies included in the review by Ohja et al. ${ }^{24)}$ can be considered as cost-minimization analysis of health expenses. Such analyses assume that two healthcare interventions (i.e. DA versus RA) have the same effectiveness and that it is possible to directly compare the costs of two approaches to understand which increases savings. Nevertheless, the assumption of equivalent effectiveness entails some limitations; a cost-effectiveness analysis would be more appropriate because it considers the possibility that two interventions may differ in effectiveness.

\section{DISCUSSION}

The rationale supporting the present article stems from the need to propose and implement more efficient care pathways for health systems whose current organizational models are not realistically sustainable in the medium to long term. It is increasingly difficult to face to the growing need for health care while resources are progressively decreasing for a number of reasons. This need matches the remarkable advances made by physical therapists, both in terms of scientific production and professional competence ${ }^{42}$.

DA is an organizational model in which the patient has no a medical filter which means physical therapists are required to have a more responsible approach and evaluate the most appropriate management for the patients (i.e. their own management or referral to a medical doctor or another professional).

This model is currently most widespread in countries that have a more deeply rooted tradition of health professions ${ }^{43)}$ and a cultural and scientific training, especially focused on health service efficiency. In these countries, the weight of professional categories appears to be less significant because of the greater objectivity of health policies adopted. 
Table 2. Safety of DA compared to RA or other interventions

\begin{tabular}{|c|c|c|c|c|c|c|}
\hline $\begin{array}{l}\text { Moore } \\
\text { et al. } 2005\end{array}$ & $\begin{array}{l}\text { Non- } \\
\text { experimental, } \\
\text { retrospective, } \\
\text { descriptive }\end{array}$ & $\begin{array}{l}\text { Different patholo- } \\
\text { gies (mainly MSD) } \\
\text { in military health } \\
\text { care facilities }\end{array}$ & DA & RA & $\begin{array}{l}\text { Adverse events } \\
\mathrm{N}^{\circ} \text { of disciplinary/legal } \\
\text { actions against a PT } \\
\mathrm{N}^{\circ} \text { of litigations against U.S. }\end{array}$ & $\begin{array}{l}\text { No adverse events reported in } \\
\text { both group } \\
\text { No disciplinary/legal actions } \\
\text { No litigation against U.S. }\end{array}$ \\
\hline $\begin{array}{l}\text { Childs } \\
\text { et al. } 2005\end{array}$ & $\begin{array}{l}\text { Cross-sec- } \\
\text { tional }\end{array}$ & MSD & $\begin{array}{l}\text { Experienced } \\
\text { PTs \& } \\
\text { PTs student }\end{array}$ & $\begin{array}{l}\text { Different } \\
\text { physicians } \\
\& \text { Medical } \\
\text { students }\end{array}$ & MSD management skill & $\begin{array}{l}\text { Higher knowledge to manage } \\
\text { MSD for experienced PTs com- } \\
\text { pared to all physician (excluded } \\
\text { orthopedics) } \\
\text { PTs students showed higher } \\
\text { knowledge than all physician } \\
\text { (excluded orthopedics) }\end{array}$ \\
\hline $\begin{array}{l}\text { Carnes } \\
\text { et al. } 2010\end{array}$ & SR & Not specified & MT & None & $\begin{array}{l}\text { Adverse events } \\
\text {-Major } \\
\text {-Mild to Moderate }\end{array}$ & $\begin{array}{l}\text { Low risk of major adverse event } \\
50 \% \text { of patients may report mi- } \\
\text { nor to moderate adverse events }\end{array}$ \\
\hline $\begin{array}{l}\text { Paanalahti } \\
\text { et al. } 2014\end{array}$ & RCT & $\begin{array}{l}\text { Neck and back } \\
\text { pain }\end{array}$ & MT & $\begin{array}{l}\text {-MT } \\
\text { without } \\
\text { SMT } \\
\text {-MT } \\
\text { without } \\
\text { stretching }\end{array}$ & $\begin{array}{l}\text { Adverse events } \\
\text {-Short/long minor } \\
\text {-Short/long moderate } \\
\text {-Serious }\end{array}$ & $\begin{array}{l}\text { No serious adverse event was } \\
\text { reported } \\
50 \% \text { of patients reported minor } \\
\text { to moderate adverse events } \\
\text { (muscle soreness). } \\
\text { No differences between groups } \\
\text { Women reports more adverse } \\
\text { events than men. }\end{array}$ \\
\hline $\begin{array}{l}\text { Maiers } \\
\text { et al. } 2014\end{array}$ & RCT & $\begin{array}{l}\text { Elderly with } \\
\text { chronic neck pain }\end{array}$ & SMT & Exercise & $\begin{array}{l}\text { Adverse events } \\
\text {-Non serious } \\
\text {-Serious }\end{array}$ & $\begin{array}{l}\text { Non serious adverse events } \\
\text { often occurred in elderly with } \\
\text { chronic neck pain } \\
\text { Serious adverse events not } \\
\text { related to SMT nor Exercise }\end{array}$ \\
\hline $\begin{array}{l}\text { Mintken } \\
\text { et al. } 2015\end{array}$ & $\begin{array}{l}\text { Retrospective } \\
\text { descriptive }\end{array}$ & MSD & DA & None & $\begin{array}{l}\text { Adverse events } \\
\text { Disciplinary/ } \\
\text { Legal action against PT }\end{array}$ & $\begin{array}{l}\text { Minimal or no risk of Adverse } \\
\text { events }\end{array}$ \\
\hline
\end{tabular}

Table 2 summary of the main literature on adverse events due to physical therapy and DA for patients with MSD. DA: direct access to physical therapy; EA: early access; LBP: low back pain; LOS: length of stay; RA: referred access by a physician; RCT: randomized controlled trial; SMT: spinal manipulative therapy; SR: systematic review

Recently scientific literature showed an increase in publications on the topic of DA and the WCPT, along with prominent national associations such as APTA, is working to increase awareness and highlight the importance of this topic ${ }^{6,7,11)}$. Data presented in this paper support DA for patients with MSD since effectiveness, safety and cost-effectiveness of DA seem to be similar or superior compared to $\mathrm{RA}^{24)}$.

Publications currently available show that DA can be a well-grounded model measuring all the results used in studies in terms of patient satisfaction, quantity of imaging tests and drugs required, number of working days missed, compliance with a physical therapy program ${ }^{24}$. These results may correlate to the fact that physiotherapists probably spend more time with their patients.

Adherence or compliance to a treatment program and the patient's coping style are two important aspects, well-known to clinicians dealing with MSD, which may partly explain the positive results shown in this paper ${ }^{29)}$ : DA as an organizational model for the management of MSD may be furthermore strengthened and supported by this issue.

Taylor et al. ${ }^{33)}$ showed the ability of the physical therapist to manage effectively and safely simple peripheral musculoskeletal injuries in the emergency department significantly reducing the length of stay, waiting and treatment time of patients.

Although the context in which the data were collected in this study concern a particular situation this organizational model could be compared or assimilated to those we commonly refer to as DA or rather provide the patient's first contact with the physical therapist, avoiding the first contact by a doctor.

Clinical research results ${ }^{24-34)}$ show that DA is more effective than RA while socio-economic data show that DA is able to keep down direct (i.e. number of tests or drugs required) and indirect costs (i.e. number of working days missed) associated with complaints caused by MSD ${ }^{38-41)}$.

The proactive aspects leading to DA development include policies aimed at DA promotion and the autonomy of physical therapists, while patient safety is the main obstacle to this "professional movement", which could define the physical therapist as the front-line health professional in MSD management. Albeit realistic, such as concern has long been used as a deterrent by those who counter DA especially for political and economic reasons. However, the school of thought arguing that there is 
potential danger in entrusting the direct management of MSD to a physical therapist is not reflected in scientific literature, as pointed out in the systematic review published by Ojha et al. ${ }^{24)}$; indeed, some authors ${ }^{32}$ suggest that the specialized training physical therapists receive in the management of MSD is an important achievement that enables them to deal with patients in DA appropriately and safely.

Considering the opportunities opened by adequate training for treating MSD patients autonomously, it would be desirable to implement undergraduate and post-graduate courses enabling physical therapists to acquire knowledge and develop the necessary expertise to master the clinical skills needed to meet this challenge.

About $69 \%$ of the 106 WCPT countries that participated in the survey in 2013 ${ }^{11)}$ confirmed that currently there are qualification courses designed to provide physical therapists with the necessary evaluation tools for autonomous practice in a perspective of self-referral by patients; based on our experience, these courses should be promoted and implemented by universities, both at the undergraduate as well as the Master of Science degree level.

From an economic point of view DA seems to be less costly than RA for the various 'stakeholders' involved in the management of $\mathrm{MSD}^{24)}$. The studies included in the review by Ohja et al. ${ }^{24)}$ can be considered as cost-minimization analysis of health expenses. Such analyses assume that two healthcare interventions (i.e. DA versus RA) have the same effectiveness and that it is possible to directly compare the costs of two approaches to understand which increases savings. Nevertheless, the assumption of equivalent effectiveness entails some limitations; a cost-effectiveness analysis would be more appropriate because it considers the possibility that two interventions may differ in effectiveness. To date, there are no published costeffectiveness studies that assessed whether DA is cost-effective, following a healthcare system or societal perspective, when compared to RA for patients with MSD. This lack in literature could be related to the ethical implications of conducting a randomized controlled trial in which patients are randomly assigned to DA or RA, without considering their values and preferences. The development of future randomized controlled trials with economic evaluations will enable us to investigate more appropriately if cost savings associated to DA correspond to equal effectiveness than RA.

Furthermore, in Italy DA may be an efficient organization approach to face MSD to provide better services. In Italy, obstacles to the spread of DA as a standard organizational model are to be found in several factors such as difficulties in adopting virtuous organizational models, lobby and the fact that physical therapist is a relatively new profession which has only recently been organized in a recognized and established university degree.

The main limitation of our study depends on the design: although it was carried out an extensive search of the literature it is not a systematic review, so that this methodological limit could impact on the validity of the results. It would be desirable that future research should focus on the effectiveness and efficiency of DA, the development of randomized controlled trials with economic evaluations will enable us to investigate more appropriately if cost savings associated to DA correspond to an equal effectiveness than RA.

From a professional point of view, the results of our review should encourage physical therapists to assess their skills in the evaluation of patients with MSD and, if necessary, fill the gaps through high quality training. This could create the necessary bottom-up process to adequately address the challenge of DA also in countries, for example Italy, where DA is still underused.

Remarkable detailed studies support DA as a reference model for MSD management. DA is more effective than a physician's referral since self-referred patients need fewer visits and pain killers (analgesic drugs) with a higher satisfaction. As for cost effectiveness DA requires few direct and indirect costs compared to the referred approach. Finally, DA is as safe as the physician's referral with more active coping resulting in greater compliance to therapeutic programs and better treatment outcomes.

Comparing DA to other interventions to manage MSD the results are similar to the comparison between direct and referred access: DA is associated with a higher patient satisfaction, comparable clinical effectiveness and an earlier time to manage patients' complaints.

Present literature regarding DA is not so far reaching nor standardized but results seem to be promising and support this organization model.

Our review offers interesting information that deserve a further in-depth analysis to understand what kind of scientific and organization developments to increase the use of DA in the Health Service.

Conflict of interests

The authors declare that they have no competing interests.

\section{ACKNOWLEDGEMENTS}

We thank Alessandro Chiarotto, PT, MSc, PhD Student at EMGO+ Health Institute for Health Care Research (Amsterdam, The Netherlands) for helping us to improve the manuscript. We also thank Giuseppe Tedesco, OMPT, BSc for reviewing the section regarding legislation about DA in Italy. 


\section{REFERENCES}

1) Global Burden of Disease Study 2013 Collaborators: Global, regional, and national incidence, prevalence, and years lived with disability for 301 acute and chronic diseases and injuries in 188 countries, 1990-2013: a systematic analysis for the Global Burden of Disease Study 2013. Lancet, 2015, 386: 743-800. [Medline] [CrossRef]

2) Hoy DG, Smith E, Cross M, et al.: The global burden of musculoskeletal conditions for 2010: an overview of methods. Ann Rheum Dis, 2014, 73: 982-989. [Medline] [CrossRef]

3) Hoy D, March L, Brooks P, et al.: The global burden of low back pain: estimates from the Global Burden of Disease 2010 study. Ann Rheum Dis, 2014 , 73 : 968-974. [Medline] [CrossRef]

4) Hoy D, March L, Woolf A, et al.: The global burden of neck pain: estimates from the global burden of disease 2010 study. Ann Rheum Dis, 2014 , 73: 1309-1315. [Medline] [CrossRef]

5) Cross M, Smith E, Hoy D, et al.: The global burden of hip and knee osteoarthritis: estimates from the global burden of disease 2010 study. Ann Rheum Dis, 2014, 73: 1323-1330. [Medline] [CrossRef]

6) WCPT What is direct access and self-referral? www.wcpt.org (Accessed May 30, 2016)

7) Apta Vision 2020. www.apta.org/vision2020 (Accessed May 30, 2016)

8) APTA. https://www.apta.org/uploadedFiles/APTAorg/Advocacy/State/Issues/Direct_Access/DirectAccessbyState.pdf (Accessed May 30, 2016)

9) Kruger J: Patient referral and the physiotherapist: three decades later. J Physiother, 2010, 56: 217-218. [Medline] [CrossRef]

10) Galley P: Physiotherapists as first-contact practitioners—new challenges and responsibilities in Australia. Physiotherapy, 1977, 63: 246-248. [Medline]

11) Direct access and self referral to physical therapy: key facts and references. http://www.wcpt.org/sites/wcpt.org/files/files/Direct_access_SR_report_Jan2013. pdf (Accessed Jan. 1, 2016)

12) Mitchell JM, de Lissovoy G: A comparison of resource use and cost in direct access versus physician referral episodes of physical therapy. Phys Ther, 1997, 77: 10-18. [Medline] [CrossRef]

13) Durant TL, Lord LJ, Domholdt E: Outpatient views on direct access to physical therapy in Indiana. Phys Ther, 1989, 69: 850-857. [Medline] [CrossRef]

14) Taylor TK, Domholdt E: Legislative change to permit direct access to physical therapy services: a study of process and content issues. Phys Ther, 1991,71 : 382-389. [Medline] [CrossRef]

15) Shoemaker MJ: Direct consumer access to physical therapy in Michigan: challenges to policy adoption. Phys Ther, 2012, 92: 236-250. [Medline] [CrossRef]

16) Bury TJ, Stokes EK: A global view of direct access and patient self-referral to physical therapy: implications for the profession. Phys Ther, 2013, 93 : $449-459$. [Medline] [CrossRef]

17) Bury TJ, Stokes EK: Direct access and patient/client self-referral to physiotherapy: a review of contemporary practice within the European Union. Physiotherapy, 2013, 99: 285-291. [Medline] [CrossRef]

18) Leemrijse CJ, Swinkels IC, Veenhof C: Direct access to physical therapy in the Netherlands: results from the first year in community-based physical therapy. Phys Ther, 2008, 88: 936-946. [Medline] [CrossRef]

19) Scheele J, Vijfvinkel F, Rigter M, et al.: Direct access to physical therapy for patients with low back pain in the Netherlands: prevalence and predictors. Phys Ther, 2014, 94: 363-370. [Medline] [CrossRef]

20) Associazione Italiana Fisioterapisti: Profilo professionale del Fisioterapista. http://aifi.net/professione/profilo-professionale (Accessed May 30, 2016)

21) B.U. 10 - 5605 Apr 2, 2007. http://www.regione.piemonte.it/governo/bollettino/abbonati/2007/17/siste/00000083.htm (Accessed May 30, 2016)

22) ISTAT. www.istat.it (Accessed May 30, 2016)

23) Regione Piemonte -sanità. http://www.regione.piemonte.it/sanita/ep/pubbli.htm (Accessed May 30, 2016)

24) Ojha HA, Snyder RS, Davenport TE: Direct access compared with referred physical therapy episodes of care: a systematic review. Phys Ther, 2014, 94: 14-30. [Medline] [CrossRef]

25) Webster VS, Holdsworth LK, McFadyen A: Self-referral, access and physiotherapy: patients' knowledge and attitudes-results of a national trial. Physiotherapy, 2008, 94: 141-149. [CrossRef]

26) Holdsworth LK, Webster VS, McFadyen A: Are patients who refer themselves to physiotherapy different from those referred by GPs? Results of a national trial. Physiotherapy, 2006, 92: 26-33. [CrossRef]

27) Hackett GI, Bundred P, Hutton JL, et al.: Management of joint and soft tissue injuries in three general practices: value of on-site physiotherapy. Br J Gen Pract, 1993, 43: 61-64. [Medline]

28) Nordeman L, Nilsson B, Möller M, et al.: Early access to physical therapy treatment for subacute low back pain in primary health care: a prospective randomized clinical trial. Clin J Pain, 2006, 22: 505-511. [Medline] [CrossRef]

29) Zigenfus GC, Yin J, Giang GM, et al.: Effectiveness of early physical therapy in the treatment of acute low back musculoskeletal disorders. J Occup Environ Med, 2000, 42: 35-39. [Medline] [CrossRef]

30) Daker-White G, Carr AJ, Harvey I, et al.: A randomised controlled trial. Shifting boundaries of doctors and physiotherapists in orthopaedic outpatient departments. J Epidemiol Community Health, 1999, 53: 643-650. [Medline] [CrossRef]

31) Taylor NF, Norman E, Roddy L, et al.: Primary contact physiotherapy in emergency departments can reduce length of stay for patients with peripheral musculoskeletal injuries compared with secondary contact physiotherapy: a prospective non-randomised controlled trial. Physiotherapy, 2011, 97: 107-114. [Medline] [CrossRef]

32) Moore JH, McMillian DJ, Rosenthal MD, et al.: Risk determination for patients with direct access to physical therapy in military health care facilities. J Orthop Sports Phys Ther, 2005, 35: 674-678. [Medline] [CrossRef]

33) Childs JD, Whitman JM, Sizer PS, et al.: A description of physical therapists' knowledge in managing musculoskeletal conditions. BMC Musculoskelet Disord, 2005, 6: 32. [Medline] [CrossRef]

34) Foster NE, Hartvigsen J, Croft PR: Taking responsibility for the early assessment and treatment of patients with musculoskeletal pain: a review and critical analysis. Arthritis Res Ther, 2012, 14: 205. [Medline] [CrossRef] 
35) Carnes D, Mars TS, Mullinger B, et al.: Adverse events and manual therapy: a systematic review. Man Ther, 2010, 15: 355-363. [Medline] [CrossRef]

36) Maiers M, Evans R, Hartvigsen J, et al.: Adverse events among seniors receiving spinal manipulation and exercise in a randomized clinical trial. Man Ther, 2015, 20: 335-341. [Medline] [CrossRef]

37) Paanalahti K, Holm LW, Nordin M, et al.: Adverse events after manual therapy among patients seeking care for neck and/or back pain: a randomized controlled trial. BMC Musculoskelet Disord, 2014, 15: 77. [Medline] [CrossRef]

38) Mintken PE, Pascoe SC, Barsch AK, et al.: Direct access to physical therapy services is safe in a university student health center setting. J Allied Health, 2015, 44: 164-168. [Medline]

39) Middleton K: Give patients direct access to physiotherapy. BMJ, 2016, 352: h6844. [Medline] [CrossRef]

40) Holdsworth LK, Webster VS, McFadyen A: What are the costs to NHS Scotland of self-referral to physiotherapy? Results of a national trial. Physiotherapy, 2007, 93: 3-11. [CrossRef]

41) Pendergast J, Kliethermes SA, Freburger JK, et al.: A comparison of health care use for physician—referred and self-referred episodes of outpatient physical therapy. Health Serv Res, 2012, 47: 633-654. [Medline] [CrossRef]

42) Plebani G: Le motivazioni delle scelte terapeutiche dei fisioterapisti italiani: studio pilota. Sci Riabilitativa, 2012, $14: 22-32$.

43) APTA History. Www.apta.org (Accessed May 30)

\section{Appendix 1.}

\section{Search strategy}

The full search strategy used on Medline and Ovid was set as follows:

Patient(s): "musculoskeletal disease"[Mesh] OR "neck pain"[Mesh] OR "neck pain"[tiab] OR "back pain”[Mesh] OR "low back pain" [Mesh] OR low back pain[tiab] OR osteoarthritis[Mesh] OR osteoarthritis[tiab] OR "osteoarthritis, knee"[Mesh] OR "osteoarthritis, spine”[Mesh] OR "osteoarthritis, hip"[Mesh]

Intervention: ("Physical Therapy Specialty"[Mesh] OR "Physical Therapy Modalities"[Mesh] OR physiotherapy[tiab] OR "physical therapy"[tiab] AND ("direct access"[tiab] OR "self-referral"[tiab] OR "referral and consultation"[Mesh])

Comparison: "usual care"[tiab] OR "medical referral"[tiab] OR "physician referral"[tiab]

Outcome(s): effectiveness[Mesh] OR "cost benefit analysis"[Mesh] OR outcome [Mesh] OR outcome [tiab] OR "patient safety"[Mesh] OR "adverse events"[tiab]. 